\title{
The biological evaluation of fusidic acid and its hydrogenation derivative as antimicrobial and anti-inflammatory agents
}

This article was published in the following Dove Press journal: Infection and Drug Resistance

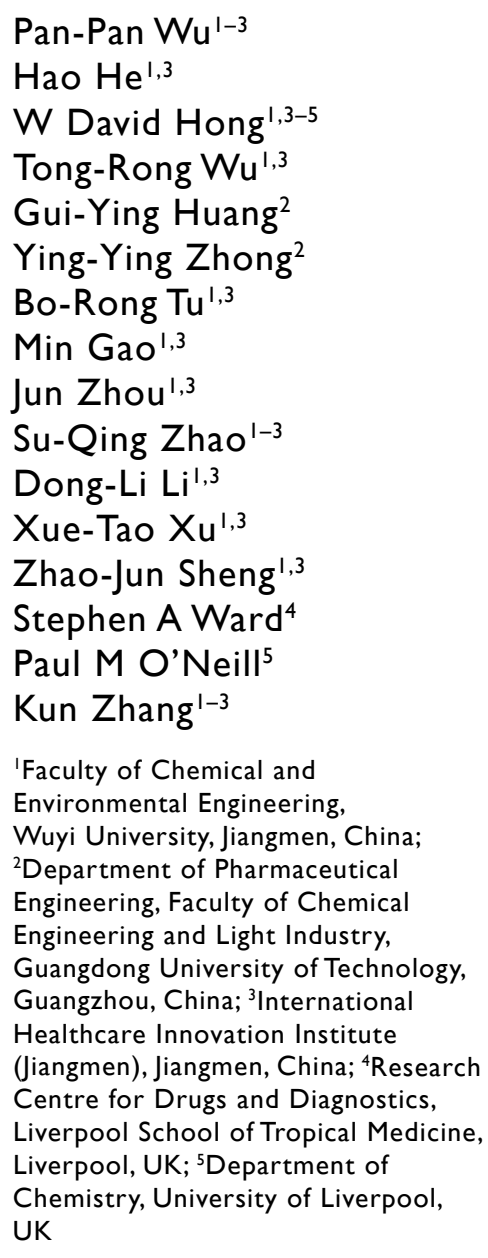

Correspondence: Su-Qing Zhao; Kun Zhang

Faculty of Chemical and Environmental Engineering, Wuyi University, No. 22 Dongcheng Village, Pengjiang District, Jiangmen, 529020, China

Tel +86 I58 2025 8676;

+86 I38 22330019

Email sqzhao@gdut.edu.cn; kzhang@gdut.edu.cn
Background: Fusidic acid (FA) (WU-FA-00) is the only commercially available antimicrobial from the fusidane family that has a narrow spectrum of activity against Gram-positive bacteria. Methods: Herein, the hydrogenation derivative (WU-FA-01) of FA was prepared and both compounds were examined against a panel of six bacterial strains. In addition, their anti-inflammatory properties were evaluated using a 12-O-tetradecanoylphorbol-13-acetate (TPA)-induced mouse ear edema model.

Results: The results of the antimicrobial assay revealed that both WU-FA-00 and WU-FA-01 displayed a high level of antimicrobial activity against Gram-positive strains. Moreover, killing kinetic studies were performed and the results were in accordance with the minimum inhibitory concentration and minimum bactericidal concentration results. We also demonstrated that the topical application of WU-FA-00 and WU-FA-01 effectively decreased TPA-induced ear edema in a dose-dependent manner. This inhibitory effect was associated with the inhibition of TPA-induced upregulation of proinflammatory cytokines IL-1 $\beta$, TNF- $\alpha$, and COX-2. WU-FA-01 significantly suppressed the expression levels of $\mathrm{p} 65$, ІкB- $\alpha$, and $\mathrm{p}-\mathrm{I} \kappa \mathrm{B}-\alpha$ in the TPA-induced mouse ear model.

Conclusion: Overall, our results showed that WU-FA-00 and WU-FA-01 not only had effective antimicrobial activities in vitro, especially to the Gram-positive bacteria, but also possessed strong anti-inflammatory effects in vivo. These results provide a scientific basis for developing FA derivatives as antimicrobial and anti-inflammatory agents.

Keywords: fusidic acid, derivative, antimicrobial, anti-inflammatory

\section{Introduction}

Over the past few decades, the appreciation of the key role of inflammation in disease diagnosis, prevention, and treatment has burgeoned. ${ }^{1,2}$ Inflammation has been defined as a complex biological response of vascular tissues to different types of harmful stimuli, 3,4 such as damaged cells, irritants, and pathogens. Inflammation has also been linked to the release of proinflammatory cytokines, ${ }^{5,6} 12-O$-tetradecanoylphorbol-13-acetate (TPA) is a well-known inducer of inflammatory, ${ }^{7,8}$ and the signal transduction pathways such as MAPK, p65, and I- $\mathrm{KB}$ kinase (IKK) activate proinflammatory transcription factors including NF- $\mathrm{KB}$, activator protein 1 (AP-1), and cAMP response elementbinding protein. ${ }^{9,10}$ These transcription factors are critically involved in the expression of various proinflammatory genes, ${ }^{11-14}$ including tumor necrosis factor-alpha (TNF- $\alpha$ ), interleukin-1 $\beta$ (IL-1 $\beta$ ), interleukin-6 (IL-6), and cyclooxygenase-2 (COX-2), all of which could be a sign of many diseases. ${ }^{4,15}$ Therefore, inflammation is a biological response, wherein the organism attempts to remove the injurious stimuli and initiate 
the healing process for the tissue; thus, it could be regarded as a protective effect. ${ }^{4}$

Currently, steroids and nonsteroidal anti-inflammatory drugs are proverbially used as effective therapeutic antiinflammatory agents in clinical applications. ${ }^{4}$ Despite the widespread use of anti-inflammatory drugs, there may be some residual risks of inflammation and the side effects of their long-term oral administration, ${ }^{16}$ especially in infectious diseases, in which patients suffer from not only the inflammatory responses but also the pathogenic microorganism infections. $^{17-19}$

Fusidic acid (FA) (WU-FA-00) (Figure 1), which has a steroid-like scaffold structurally and is derived from the fungus Fusidium coccineum, is the only marketed antibiotic from the fusidane family. Sodium fusidate, the sodium salt of FA, was primarily introduced into practice as an antistaphylococcal therapy in $1962 .{ }^{20-22}$ However, FA has a narrow spectrum of biological activity against some anaerobic Gram-negative organisms and most Gram-positive bacteria, especially the staphylococci, including the methicillinresistant Staphylococcus aureus (MRSA) and coagulasenegative staphylococci. ${ }^{23-25}$ Although some antimicrobial activity and reasonable anti-inflammatory effects have been discovered, ${ }^{26,27}$ there is no in-depth study of FA and its derivatives as potential anti-inflammatory agents. Therefore, the therapeutic efficacy of FA and its derivatives as antimicrobial and anti-inflammatory agents should be explored.

In the present study, the in vitro antimicrobial activities of FA and its hydrogenation derivative (WU-FA-01) were investigated against six bacterial strains, including five Grampositive bacterial strains and one Gram-negative bacteria strain. In parallel, TPA was used as an inducer to explore both compounds' inhibitory activity on skin inflammation in a mouse ear edema model. ${ }^{28-30}$ Moreover, immunohistochemical analysis was introduced to reveal their inhibitory effects on the expression of TPA-induced TNF- $\alpha$, IL- $1 \beta$, and COX- 2 in mouse ears. Furthermore, the anti-inflammatory mechanisms of FA and its hydrogenation derivative were also discussed to gain insight into their effects. Accordingly, FA is already a licensed antimicrobial with well-described anti-inflammatory properties. Its 24,25-dihydrofusidic acid derivative could be developed as antimicrobial with well anti-inflammatory agents.

\section{Materials and methods Chemicals}

FA was purchased from Macklin Co., Ltd. (Shanghai, China), with over 98\% purity. TPA was ordered from Sigma-Aldrich Co. (St Louis, MO, USA). TPA, FA, and its derivative were dissolved in acetone to produce the desired concentrations of each compound. TNF- $\alpha$ and IL- $1 \beta$ antibodies were purchased from Bioss Biotechnology Co. (Beijing, China) and Beyotime Biotechnology Co. (Beijing, China). The silica gel (200-300 mesh) used in the column chromatography was supplied by Inno-chem Co., Ltd. (Beijing, China). All other reagents and solvents were purchased from Adamas Reagent Ltd. (Shanghai, China) or other commercial suppliers in their analytically or chemically pure forms and used without purification. All of the compounds used in this study were diluted in acetone or dimethyl sulfoxide (DMSO) to get a stock solution for further dilution to obtain the final concentration. Thin-layer chromatography (TLC) was performed on precoated silica gel $\mathrm{F}_{254}$ plates (0.25 mm; Merck Millipore, Billerica, MA, USA); the starting material and the product were detected by either viewing under UV light or treating with an ethanolic solution of $p$-anisaldehyde spray followed by heating. Mueller Hinton agar (MHA) and Mueller Hinton broth (MHB) were purchased from Guangdong Huankai Microbial Sci. \& Tech. Co., Ltd. (Guangdong, China). The antimicrobial activity was determined by using a Multimode Plate Reader (Infinite 200, TECAN, Guangzhou, Guangdong, China).

\section{Preparation of WU-FA-0 I}

A $100 \mathrm{~mL}$ glassware was flamed-dried and allowed to cool in a desiccator before use. FA (1.0 g, $1.94 \mathrm{mmol})$ was
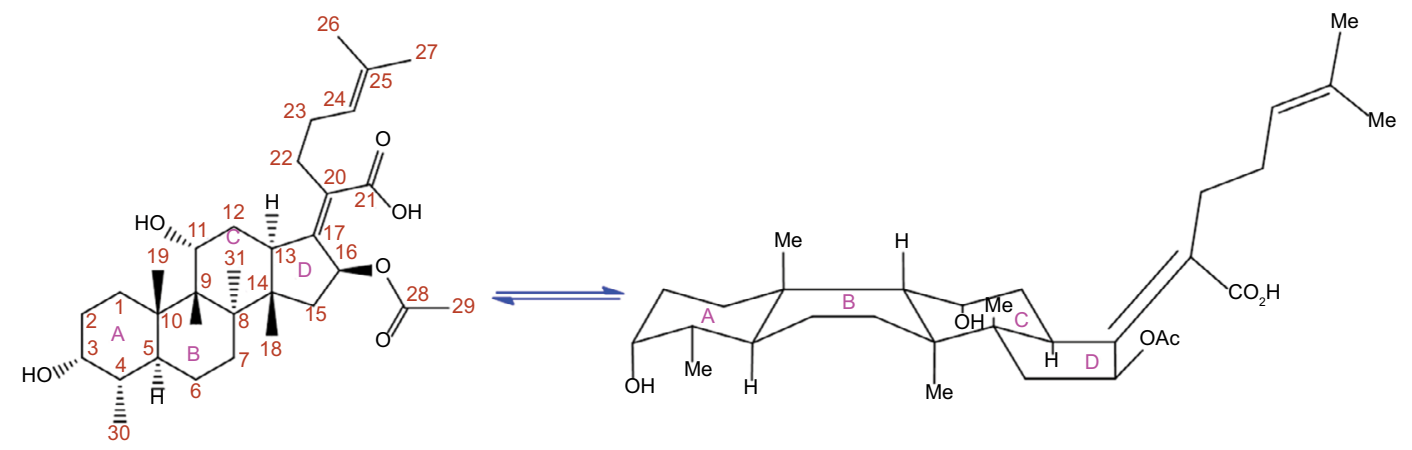

Figure I Chemical structure and conformation of fusidic acid (WU-FA-00) 
dissolved in $50 \mathrm{~mL}$ of ethanol. About $5 \%$ of palladium on calcium carbonate $(0.1 \mathrm{~g}, 0.19 \mathrm{mmol})$ was added to the reaction. Moreover, the reaction mixture was subjected to a vacuum-nitrogen purge and left to stir under a hydrogen atmosphere for 3 hours. TLC was eluted in the mixture of ethyl acetate:petroleum ether $=1: 2(\mathrm{v}: \mathrm{v})$ and stained in $p$-anisaldehyde. $R_{\mathrm{f}}$ value of the starting material was 0.14 and the product was 0.17 . Then, the reaction mixture was filtered through a pad of Celite and washed with ethyl acetate. The solvent was removed under vacuum to obtain a white solid (yield: $>98 \%$ ).

\section{Microorganisms and culture conditions}

Six bacterial strains were used for the bioassays, including three Gram-positive species, S. aureus (ATCC 6538), S. aureus subsp. aureus (ATCC 29213), S. epidermidis (ATCC 12228), Listeria monocytogenes (ATCC 19115), and Streptococcus pneumoniae (ATCC 49619), and one Gram-negative species, Escherichia coli (CMCC 44102). All bacteria were maintained on MHA, and the cultures were stored at $4^{\circ} \mathrm{C}$ and subcultured every week.

\section{Agar disk diffusion method}

The antimicrobial activity of WU-FA-00 and WU-FA-01 was determined according to the standard agar disk diffusion method with a slight modification. ${ }^{33-35}$ A 0.5 McFarland $\left(1 \times 10^{7}-1 \times 10^{8} \mathrm{CFU} / \mathrm{mL}\right)$ concentration of the bacterial suspension was uniformly inoculated onto MHA solidified in $120 \mathrm{~mm}$ Petri dishes. Once the dishes were prepared, $6 \mathrm{~mm}$ diameter discs of filter paper containing $5 \mu \mathrm{L}$ of the examined compound, which had been diluted 10 times with DMSO, were pressed gently against the surface of the agar. Discs containing WU-FA-00 were used as the positive control, while DMSO was used as the negative control. The dishes were incubated in a constant temperature incubator at $37^{\circ} \mathrm{C}$ for 24 hours. The inhibition zone (IZ) diameter was measured by a vernier caliper. All the experiments were performed in triplicate.

\section{Broth microdilution method}

The minimum inhibitory concentration (MIC) and the minimum bactericidal concentration (MBC) were determined by a microdilution method in 96-microwell plates according to the Clinical and Laboratory Standards Institute (CLSI), with a slight modification. ${ }^{36,37}$ A dilution series of the test compounds were obtained with DMSO as the solvent by twofold serial dilution. The final concentrations of the test compound were $1-400 \mu \mathrm{g} / \mathrm{mL}$. Each well received $5 \mu \mathrm{L}$ of a specific concentration of the compound and $195 \mu \mathrm{L}$ of $\mathrm{MHB}$ inoculated with the test microorganism $\left(1.5 \times 10^{5} \mathrm{CFU} / \mathrm{mL}\right)$; the final concentration of the test compound reached $0.025-10 \mu \mathrm{g} / \mathrm{mL}$. WU-FA-00 and DMSO were treated as a positive control and a negative control, respectively. The microplates were incubated in a bacteriological oven for 24 hours at $37^{\circ} \mathrm{C}$, and the drug susceptibility results were monitored by measuring the absorbance at $600 \mathrm{~nm}$ using a Multimode Plate Reader (Infinite 200). The lowest concentration without visible growth was defined as the MIC.

The MBCs were determined based on the MIC results: ${ }^{38,39}$ serial sub-cultivation of a $5 \mu \mathrm{L}$ of aliquot near the $\mathrm{MIC}$ in microtiter plates containing $195 \mu \mathrm{L}$ of $\mathrm{MHB}$ per well and incubation for 24 hours at $37^{\circ} \mathrm{C}$. The lowest concentration of antimicrobial agent that killed at least $99.9 \%$ of the starting inoculum was defined as the MBC end point, which was determined as the lowest concentration with no visible growth by measuring the absorbance at $600 \mathrm{~nm}$ using a Multimode Plate Reader (Infinite 200). All experiments were conducted in triplicate.

\section{Killing kinetic studies}

The killing kinetic assay on the Gram-positive strains, ${ }^{36,40,41}$ including S. aureus (ATCC 6538), S. aureus subsp. aureus (ATCC 29213), and S. epidermidis (ATCC 12228), was performed against WU-FA-00 and WU-FA-01 in 96-microwell plates, and six different concentrations $(0,0.025,0.1,0.3125$, 0.625 , and $1.25 \mu \mathrm{g} / \mathrm{mL}$ ) of each compound were tested. The microplates were incubated for 24 hours at $37^{\circ} \mathrm{C}$, and the growth of bacteria was monitored by measuring the absorbance at $600 \mathrm{~nm}$ using a Multimode Plate Reader (Infinite 200) every 1 hour.

\section{Animals, diets, and treatments}

Female Kunming mice (Guangdong, China) are the most productive and used mice in China, which are from Swiss mice; mice weighing approximately $22-25 \mathrm{~g}$ were used in the TPA-induced in vivo model. All animals were supplied by the Experimental Animal Center of Guangdong Province. They were maintained at $25 \pm 1^{\circ} \mathrm{C}$ with standard mouse chow diet and tap water ad libitum and were kept on a regular light-dark cycle with $50 \%$ relative humidity. All the animal experiments were performed according to the Ethical Regulations on Animal Research of Southern Medical University (approval documents: SCXK/20130002). 


\section{TPA-induced skin inflammation in mouse}

The mice were divided into nine groups: each group consisted of six mice, including a blank group, a TPA group, a dexamethasone group, and six groups for WU-FA-00 and WU-FA- 01 . In the mouse ear edema model, $20 \mu \mathrm{L}$ of acetone vehicle was topically applied to the right ear and $20 \mu \mathrm{L}$ of the treatment compounds at three different concentrations, which were dissolved in acetone, were used 5 minutes later after $20 \mu \mathrm{L}$ of TPA $(0.125 \mu \mathrm{g} / \mathrm{mL}$ in acetone $)$ was previously applied to induce the inflammation model..$^{42,43}$ Dexamethasone at a concentration of $2,500 \mu \mathrm{g} / \mathrm{mL}(6.37 \mu \mathrm{mol} / \mathrm{mL})$ in acetone was used as the positive control. Then, all of the mice were maintained at a standard condition and sacrificed 6 hours after TPA treatment. Two ear punches $(9 \mathrm{~mm}$ in diameter) from the right and left ears were then harvested immediately and weighted; the left ear was used for comparison. All experiments were carried out in compliance with the relevant laws and institutional guidelines, which were approved by the Southern Medical University (approval documents: SCXK/20130002).

\section{Histological appearance of mouse ears}

The right ear punches were fixed in $10 \%$ neutral buffered formalin, decalcified in EDTA buffer, subjected to a series progression of dehydration and embedded in paraffin. Sections of $9 \mathrm{~mm}$ were cut by using a microtome and were mounted on colorfrost microslides (VWR Scientific, Edmonton, AB, Canada). The sections were dried overnight and stained with $\mathrm{H} \& \mathrm{E}$ in accordance with the classical methods of histology. Images of the sections representing each treatment group were observed under a microscope (Olympus Corporation, Tokyo, Japan) to evaluate the damage of ear tissue.

\section{Scoring the expression of biomarkers}

Each histological type of lesion in the TPA-induced ear model was scored independently by two experienced investigators who were not aware of the identity of the specimens $(\times 200){ }^{42,44}$ The staining intensity was scored as follows: 0 , no staining; $1+$, faint; $2+$, moderate; and 3+, strong. 1+, 2+, and 3+ were recorded as 1 , 2 , and 3 points, respectively. The staining extent was graded as follows: 0 , no staining; $1+, \leq 25 \%$ of positive cells; $2+, 26-50 \%$ of positive cells; and $3+, \geq 51 \%$ of positive cells.

\section{Immunohistochemical detection of TNF- $\alpha$, IL-I $\beta$, COX-2, p65, IKB- $\alpha$, and $\mathrm{p}-\mathrm{I} \mathrm{K} \mathrm{B}-\alpha$ expressions}

The ear punch tissues were fixed in formalin, and paraffinized sections of $5 \mu \mathrm{m}$ thickness were incubated with $1.2 \% \mathrm{H}_{2} \mathrm{O}_{2}$ in
PBS to quench the endogenous peroxidase activity in order to minimize the nonspecific staining. Then, the sections were washed three times ( 5 minutes each) with 1 equal of TBST $(0.05 \%$ Tween-20). Subsequently, the primary antibody of a proliferating cell nuclear antigen was diluted 100 times, applied to each section, and left overnight at $4^{\circ} \mathrm{C}$. The sections were washed with PBS and incubated with a biotinconjugated horseradish peroxidase antibody $(1: 200)$ for 1 hour at room temperature. Finally, peroxidase was detected using the 3,3-diaminobenzidine tetrahydrochloride reaction, which produced a brown label in the epidermal tissue. The cells that stained positive for TNF- $\alpha$, IL-1 $1 \beta$, and COX-2 were counted in the section of the mouse ear using the Image-Pro Plus (Version 6.0) software. ${ }^{42}$ The results were expressed as the number of stained cells. Immunohistochemical analysis of $\mathrm{p} 65$, IкB- $\alpha$, and $\mathrm{p}-\mathrm{I} \kappa \mathrm{B}-\alpha$ was also conducted to gain insight into the signaling pathway of WU-FA- 00 and WU-FA- 01 in the TPA-induced mouse ear edema model.

\section{Statistical analysis}

The results are expressed as the mean \pm standard error (SE) or SD. Statistical comparisons among groups were performed using the Dunnett's multiple test. Statistical significance was defined by a $P$-value of $<0.05$.

\section{Results and discussion Chemistry}

To obtain the hydrogenation derivative of FA, structural modifications (according to a previous study) were made at the double bond position of C-24 and C-25. ${ }^{31}$ The synthetic route is shown in Scheme 1. The 24,25-dihydrofusidic acid (WU-FA-01) was prepared by palladium-catalyzed hydrogenation in quantitative yielding. Its structure was confirmed by high-resolution mass spectrometry, CHNS-O elemental analyzer, ${ }^{1} \mathrm{H} \mathrm{NMR}$, and ${ }^{13} \mathrm{C} \mathrm{NMR}$, and it was in accordance with the previous research. ${ }^{31}$

\section{Antibacterial activity}

The antibacterial activity of WU-FA-00 and WU-FA-01 was tested against six microorganisms, including reference strains consisting of Gram-negative bacteria and Gram-positive bacteria. All bacterial strains were cultured in $\mathrm{MHA}$ at $37^{\circ} \mathrm{C}$ overnight.

\section{Agar disk diffusion method}

The results of the antimicrobial activity of WU-FA-00 and WU-FA-01 against six different microorganisms are summarized in Table 1. Two different concentrations were examined 


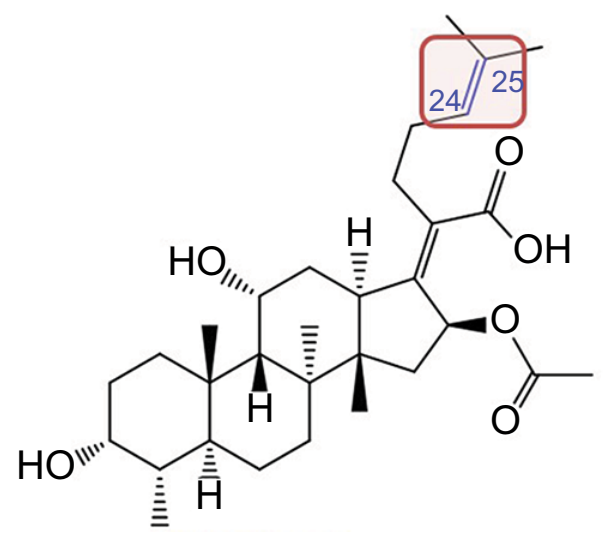

WU-FA-00

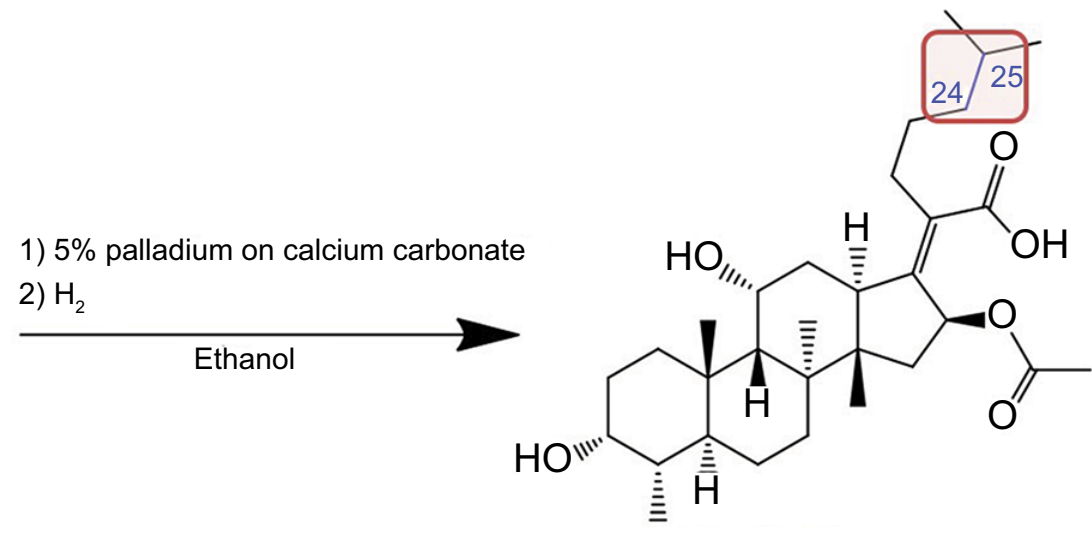

WU-FA-01

Scheme I Synthesis of the hydrogenation derivative of fusidic acid (WU-FA-0I).

Table I Antibacterial activity of WU-FA-00 and WU-FA-0I expressed in the inhibition zone (mm)

\begin{tabular}{|c|c|c|c|c|}
\hline Compound & WU-FA-00 & & WU-FA-0I & \\
\hline Structure & & & & \\
\hline Concentration $(\mu \mathrm{g} / \mathrm{mL})$ & 25 & 12.5 & 25 & 12.5 \\
\hline Dosage $(\mu \mathrm{g})$ & 0.125 & 0.0625 & 0.125 & 0.0625 \\
\hline Bacterium & Inhibition zor & & & \\
\hline $\begin{array}{l}\text { Staphylococcus aureus } \\
\text { (ATCC 6538) }\end{array}$ & $23.09 \pm 0.37$ & $20.60 \pm 0.40$ & $23.08 \pm 1.13$ & $20.05 \pm 0.30$ \\
\hline $\begin{array}{l}\text { Staphylococcus aureus subsp. aureus } \\
\text { (ATCC 29213) }\end{array}$ & $21.48 \pm 0.36$ & $18.75 \pm 0.44$ & $19.93 \pm 1.03$ & $17.10 \pm 0.14$ \\
\hline $\begin{array}{l}\text { Staphylococcus epidermidis } \\
\text { (ATCC 12228) }\end{array}$ & $24.22 \pm 1.66$ & $20.04 \pm 0.35$ & $22.91 \pm 0.84$ & $17.42 \pm 0.40$ \\
\hline $\begin{array}{l}\text { Listeria monocytogenes } \\
\text { (ATCC } 19115 \text { ) }\end{array}$ & $11.63 \pm 1.33$ & $10.44 \pm 0.82$ & $\mid \mathrm{I} .49 \pm 0.4 \mathrm{I}$ & $10.55 \pm 1.20$ \\
\hline $\begin{array}{l}\text { Streptococcus pneumoniae } \\
\text { (ATCC 49619) }\end{array}$ & $8.22 \pm 0.79$ & $7.37 \pm 1.23$ & $9.39 \pm 0.90$ & $7.52 \pm 1.11$ \\
\hline $\begin{array}{l}\text { Escherichia coli } \\
\text { (CMCC 44I02) }\end{array}$ & ND & ND & ND & ND \\
\hline
\end{tabular}

Note: Data are presented as mean \pm standard deviation.

Abbreviation: ND, not detected.

in this method. The sizes of the IZ indicated that the tested compounds with Gram-positive bacterial strains were larger than those with Gram-negative strains, and both compounds showed dose dependence. The IZ diameter was in the range of $10.37 \pm 1.23-24.22 \pm 1.66 \mathrm{~mm}$ for Gram-positive strains. However, both WU-FA-00 and WU-FA-01 showed no inhibitory effect against the Gram-negative strains. Furthermore, the screening of the antimicrobial potential of the two compounds revealed that reducing the double bond to a single bond at positions C-24 and C-25 could retain their antimicrobial activities, specifically against the Gram-positive strains.

\section{Broth microdilution method}

A microtiter plate dilution method was conducted to determine the MIC and the MBC in a 96-well plate. At the end of the incubation period, the plates were evaluated for the 
presence or absence of bacterial growth. Each sample concentration was tested four times against each microorganism. WU-FA-00, the parent compound, was employed as a positive control against bacterial growth. The final concentration of DMSO in the 96-plate well had no effect on the bacterial growth.

WU-FA-00 and WU-FA-01, the two tested compounds, were found to be active against the microorganisms studied, especially the Gram-positive bacteria. The MIC and MBC values of the two compounds were determined according to the results of the microdilution method (Table 2). The results suggested that WU-FA-01 $(\mathrm{MIC}=0.1-0.625 \mu \mathrm{g} /$ $\mathrm{mL}, \mathrm{MBC}=0.2-1.25 \mu \mathrm{g} / \mathrm{mL})$ showed activity similar to its parent compound WU-FA-00 $(\mathrm{MIC}=0.1-0.625 \mu \mathrm{g} /$ $\mathrm{mL}, \mathrm{MBC}=0.3125-1.250 \mu \mathrm{g} / \mathrm{mL})$ and indicated that the double bond at C-24 and C-25 positions in WU-FA-00 structure has little effect on its antibacterial activity. In contrast, both WU-FA-00 and WU-FA-01 were more effective against Gram-positive strains of Staphylococcus than the Gram-negative strains, and this result is in accordance with the previous agar disk diffusion studies and implied that WU-FA-01 could be developed as an active antibacterial agent.

\section{Killing kinetic studies}

The time killing studies were carried out over a period of 24 hours; bacteria were exposed to the tested compound at four different concentrations, which were determined according to their MICs. Figure 2 displays the time-kill curves of the tested compounds for S. aureus (ATCC 6538), S. aureus subsp. aureus (ATCC 29213), and Staphylococcus epidermidis (ATCC 12228). As shown in Figure 2, the MICs of the tested compounds were sufficient to inhibit almost all of the bacterial growth but with a slight increase after 20 hours during this assay. Similar to the MBC results, no remarkable difference in the bacterial counts was found after incubation for 24 hours at MICs and the results confirmed that the MBCs were highly effective for killing bacteria. Furthermore, the bacterial population incubated with DMSO or with the test compounds, which were lower than that of their MICs, indicated less inhibitory action upon all selected bacterial strains. Moreover, Figure 2 indicates that there is no difference in the observation of bacterial killing at higher concentrations of both compounds.

\section{Inhibitory effects of WU-FA-00 and WU- FA-OI on TPA-induced edema in a mouse ear model}

A TPA-induced ear edema mouse model was utilized to evaluate the in vivo anti-inflammatory activities of WU-FA00 and WU-FA-01. It has been reported that TPA, which was normally adopted in this investigation model, is a wellknown promoter of skin inflammation. The average weight of the ear punches is an important indicator that reflects the degree of skin edema when compared with the vehicle control group. As shown in Figure 3, the weight of mouse ear punches was significantly increased to $160.90 \%$ after 6 hours when $20 \mu \mathrm{L}$ of TPA $(0.125 \mu \mathrm{g} / \mathrm{mL}$ in acetone $)$ was topically applied compared to the acetone-treated control group. Topical application of 2,000, 4,000, and 8,000 $\mu \mathrm{g} /$ mL of WU-FA-00 after TPA treatment modestly inhibited TPA-induced ear edema by $39.04,73.46$, and $83.83 \%$, respectively, compared with the TPA group. However, $2,000,4,000$, and $8,000 \mu \mathrm{g} / \mathrm{mL}$ of WU-FA-01 significantly decreased the TPA-induced ear edema by 48.16, 113.97, and $137.32 \%$, respectively, in a dose-dependent manner.

Table 2 Antibacterial activities of WU-FA-00 and WU-FA-0I expressed in MIC and MBC $(\mu \mathrm{g} / \mathrm{mL})$

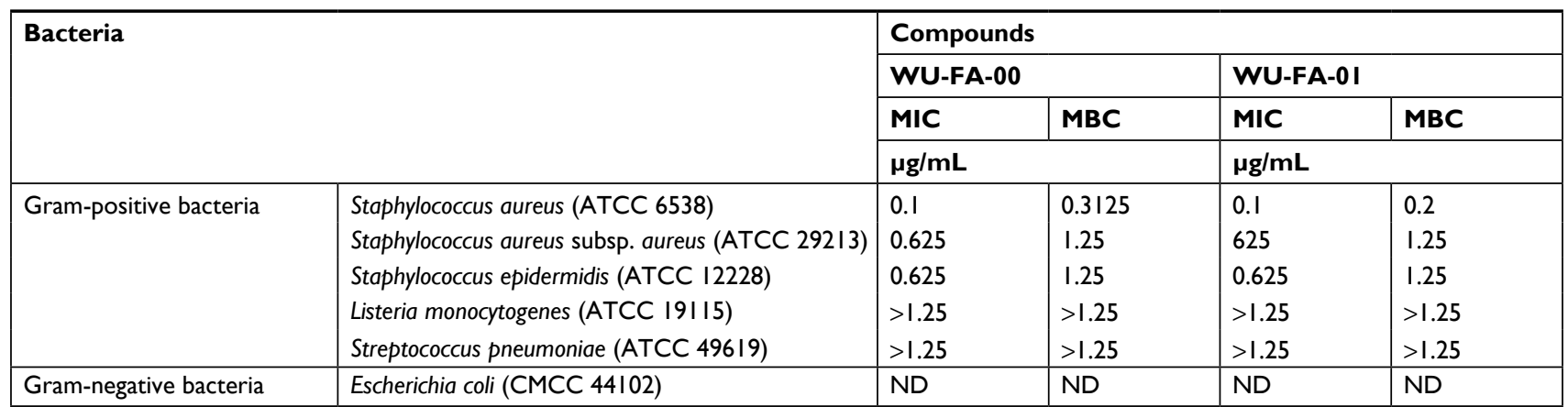

Notes: MIC $(\mu \mathrm{g} / \mathrm{mL})$, ie, the lowest concentration of the compound that completely inhibits the growth of bacteria. $\mathrm{MBC}(\mu \mathrm{g} / \mathrm{mL})$, ie, the lowest concentration of the compound that completely kills the bacteria.

Abbreviations: MBC, minimum bacterial concentration; MIC, minimum inhibitory concentration; ND, not detected. 

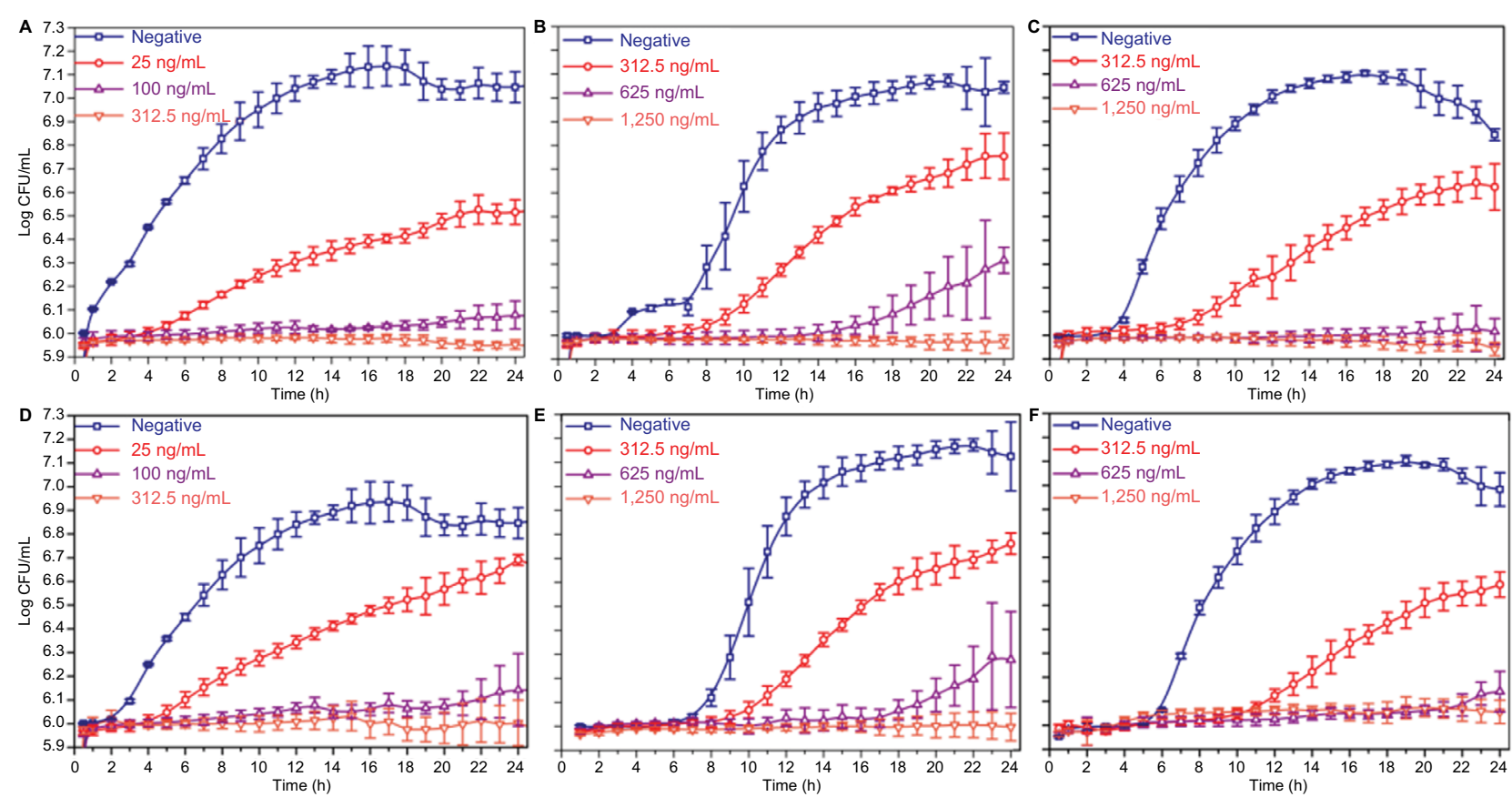

Figure 2 Time-kill curves for the three Gram-positive strains.

Notes: Staphylococcus aureus (ATCC 6538) (A and D), Staphylococcus epidermidis (ATCC 12228) (B and E), and S. aureus subsp. aureus (ATCC 292 I3) (C and F), exposed to four different concentrations of WU-FA-00 (A-C) and WU-FA-0I (D-F) according to their respective MICs $(n=4)$.

Abbreviation: MIC, minimum inhibitory concentration.
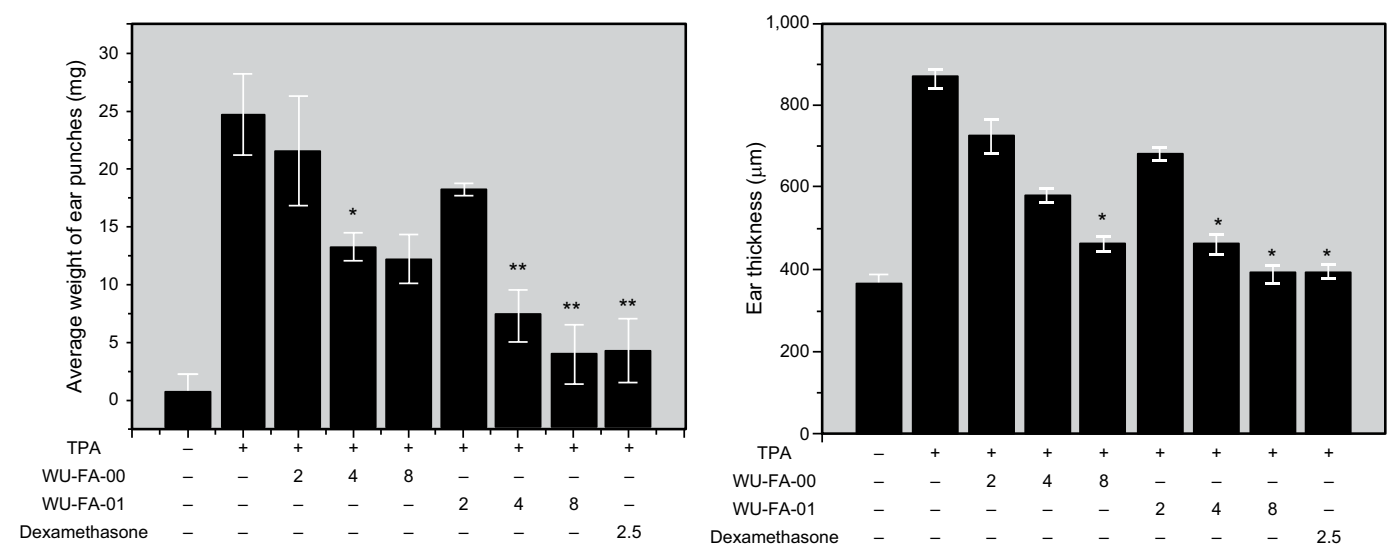

Figure 3 Inhibition effects of WU-FA-00 and WU-FA-0I on TPA-induced edema in mouse ears.

Notes: The right ears of all animals $(n=6)$ were topically treated with $20 \mu \mathrm{L}$ of acetone (vehicle control) or WU-FA-00/WU-FA-0I (2, 4, or 8 mg/mL)/Dexamethasone $(2.5 \mathrm{mg} / \mathrm{mL})$ in $20 \mu \mathrm{L}$ of acetone after the application of TPA $(2 \mathrm{mg} / \mathrm{mL})$ in $20 \mu \mathrm{L}$ of acetone. The mice were sacrificed 6 hours after the TPA treatment. Both ear punches ( $9 \mathrm{~mm}$ in diameter) were immediately taken, and then, they were weighted and measured. The data from each group are expressed as mean \pm SD. Compared to the TPAinduced model group $(n=6), * P<0.05$ and $* * P<0.01$ (Dunnett's multiple comparison test). The minus symbols mean not present, the plus symbols mean present.

Abbreviation: TPA, 12-O-tetradecanoylphorbol-13-acetate.

Furthermore, the compound WU-FA-01 had a similar effect on the positive control when it was used at a dose of $4,000 \mu \mathrm{g} / \mathrm{mL}(7.71 \mu \mathrm{mol} / \mathrm{mL})$ with an inhibition rate of $113.97 \%$, whereas dexamethasone had an inhibition rate of $134.13 \%$ at a dose of $2,500 \mu \mathrm{g} / \mathrm{mL}(6.37 \mu \mathrm{mol} / \mathrm{mL})$.
There is no significant difference between the two fusidane compounds from the statistical comparison (Figure 3); all right ear punches were adopted as a standard to evaluate the increase in the average weight and thickness of ear punches. This result also suggested that WU-FA-01 had stronger 
protective effects than WU-FA-00 against TPA-induced skin inflammation.

\section{Inhibitory effects of WU-FA-00 and WU-FA-OI on the histological appearance of mouse ears}

To investigate the role of WU-FA- 00 and WU-FA- 01 in the histological appearance of a TPA-induced mouse ear model, both WU-FA-00 and WU-FA-01 were evaluated by transdermal application. In this model, the right ears of each group of mice were pretreated with $20 \mu \mathrm{L}$ of TPA $(0.125 \mu \mathrm{g} / \mathrm{mL}$ in acetone), while the controls were topically adopted with acetone. The treatment compounds $(20 \mu \mathrm{L})$ at three different concentrations were dissolved in acetone and used 5 minutes later. Dexamethasone was used as a positive control at a concentration of $2,500 \mu \mathrm{g} / \mathrm{mL}(6.37 \mu \mathrm{mol} / \mathrm{mL})$ in acetone, which is more comparable to the dosage of two tested fusidane compounds. After the ear tissues had been stained with H\&E stain, as shown in Figure 4, the histological appearances of the ear sections indicated that the ears treated with acetone alone appeared normal in the epidermal layer without any obvious lesion. However, the TPA alone group displayed significant swelling, which was consistent with the results of the ear thickness and the ear punch weight (Figure 3). Moreover, the topical application of WU-FA-00 and WU-FA-01 could effectively suppress signs of the inflammatory response, such as epidermal hyperplasia and dense dermal leukocyte infiltration.

\section{Inhibition of TPA-induced expression of TNF- $\alpha$, IL-I $\beta$, and COX-2}

To gain insight into the molecular mechanisms by which WU-FA-00 and WU-FA-01 suppressed TPA-induced skin inflammation, we examined the effects of both WU-FA- 00 and WU-FA-01 on the expression levels of proinflammatory cytokines, including TNF- $\alpha$, IL- $1 \beta$, and COX-2, in mouse ears using immunohistochemical analysis. As shown in Figure 5, the expression level of proinflammatory cytokines at red arrows (TNF- $\alpha$, IL-1 $\beta$, and COX-2) were dramatically elevated 6 hours after topical stimulation with TPA, which was apparently downregulated in a dose-dependent manner by treatment with WU-FA-00 and WU-FA-01. However,
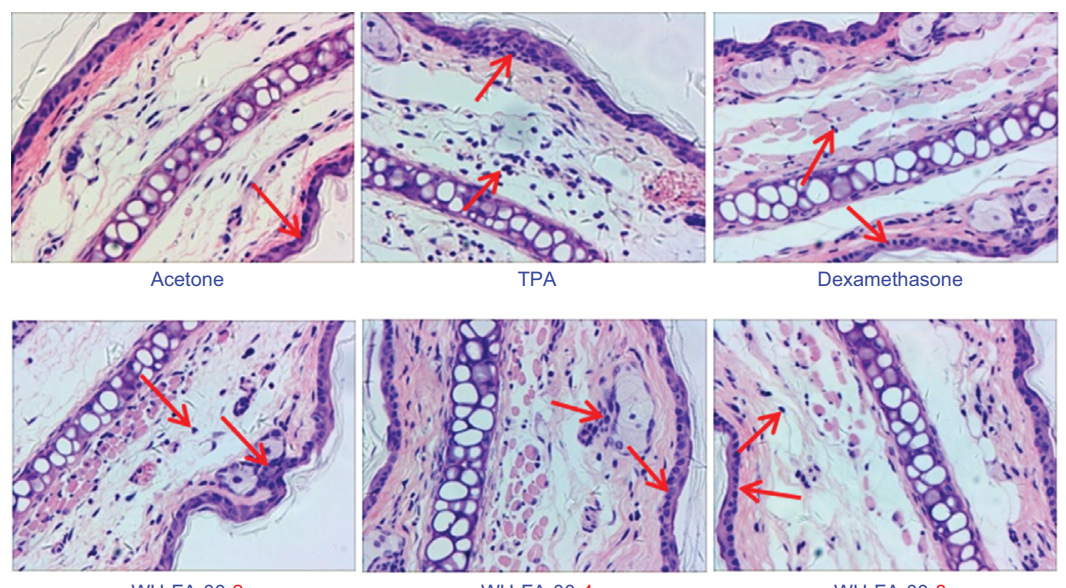

WU-FA-00-2

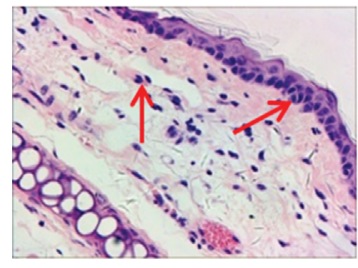

WU-FA-01-2

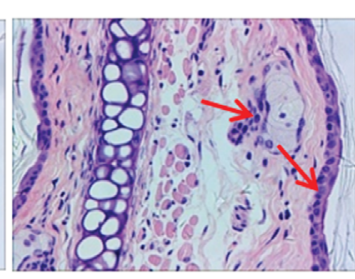

WU-FA-00-4

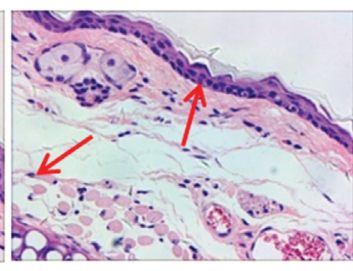

WU-FA-01-4

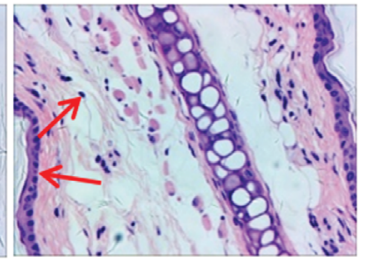

WU-FA-00-8

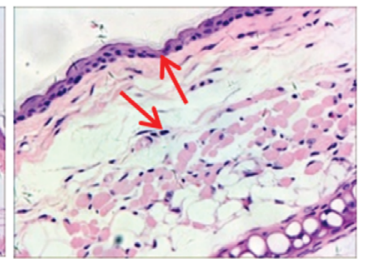

WU-FA-01-8

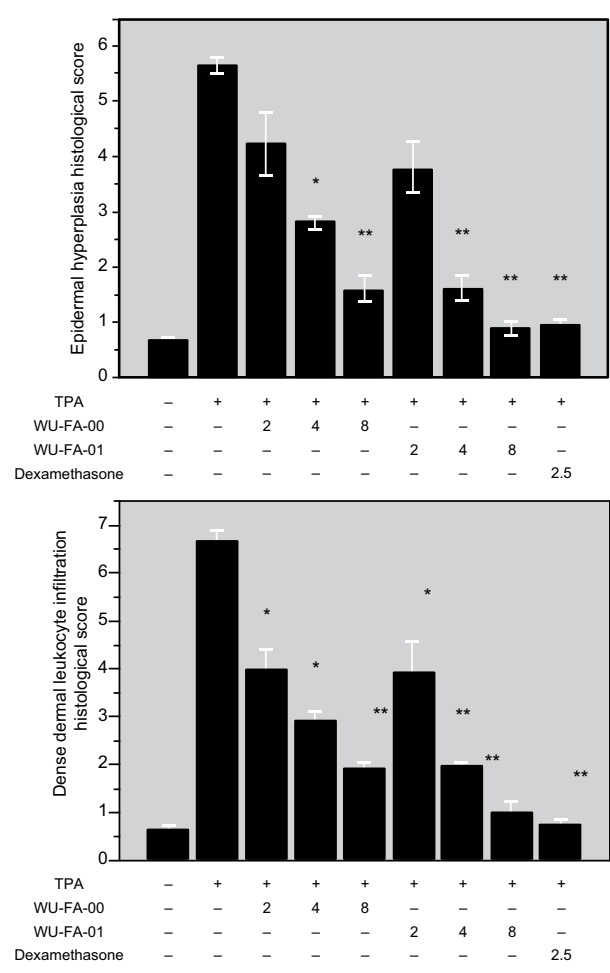

Dexamethason

Figure 4 H\&E staining for histological changes in TPA-induced mouse ears treated with an acetone control, TPA, WU-FA-00, and WU-FA-0I at different concentrations. Notes: The data from each group are expressed as mean \pm SD. Compared to the TPA-induced model group $(n=6)$, $* P<0.05$, $* * P<0.01$ (Dunnett's multiple comparison test). Magnification 200x. The arrows indicate the lesion or swelling or epidermal hyperplasia or dense dermal leukocyte infiltration of the ear tissues.

Abbreviation: TPA, 12-O-tetradecanoylphorbol-13-acetate. 
A

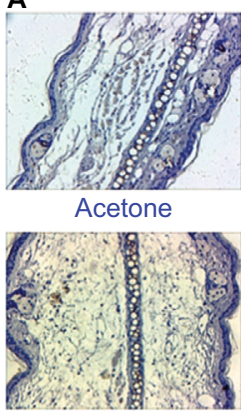

WU-FA-00-2

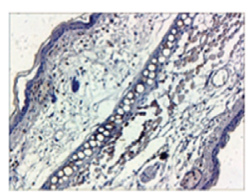

WU-FA-01-2

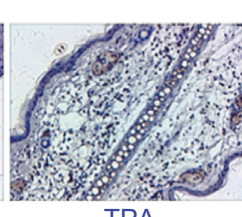

TPA

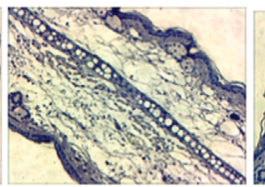

WU-FA-00-4

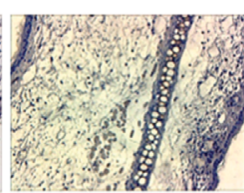

WU-FA-01-4
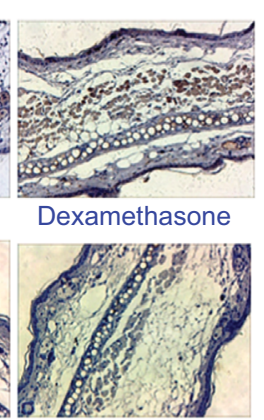

WU-FA-00-8

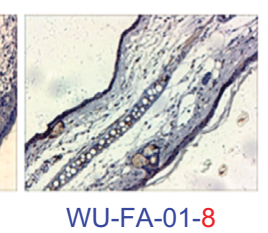

B

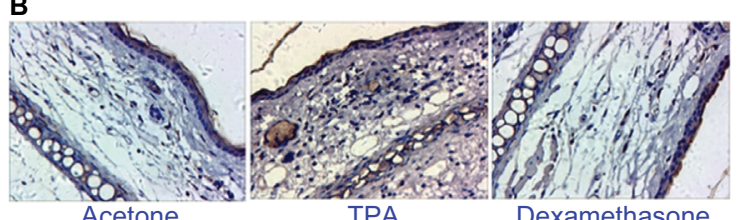

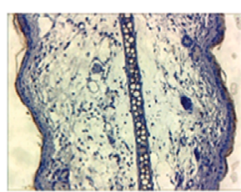

WU-FA-00-2

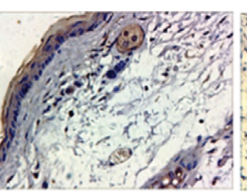

WU-FA-01-2

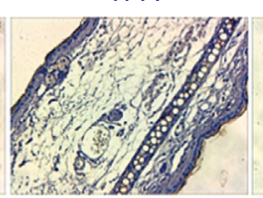

WU-FA-00-4

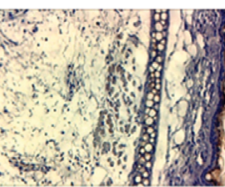

WU-FA-01-4
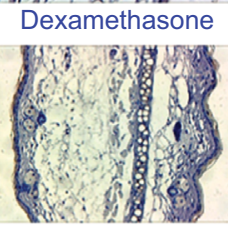

WU-FA-00-8

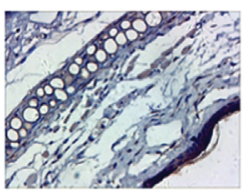

WU-FA-01-8

C

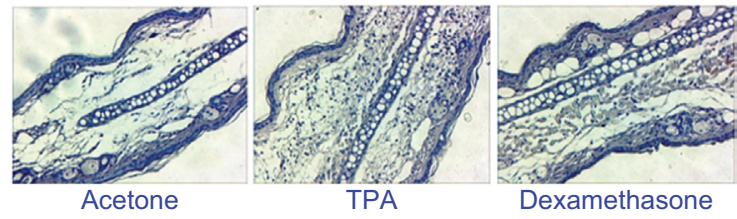

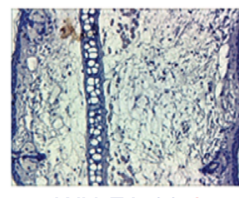
WU-FA-00-2

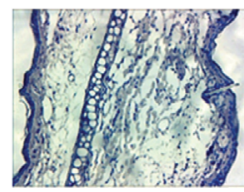

WU-FA-01-2

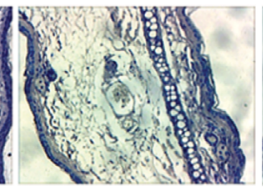

WU-FA-00-4

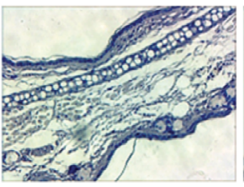

WU-FA-01-4

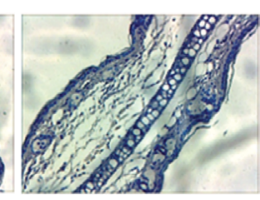

WU-FA-00-8

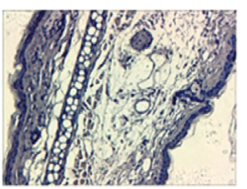

WU-FA-01-8
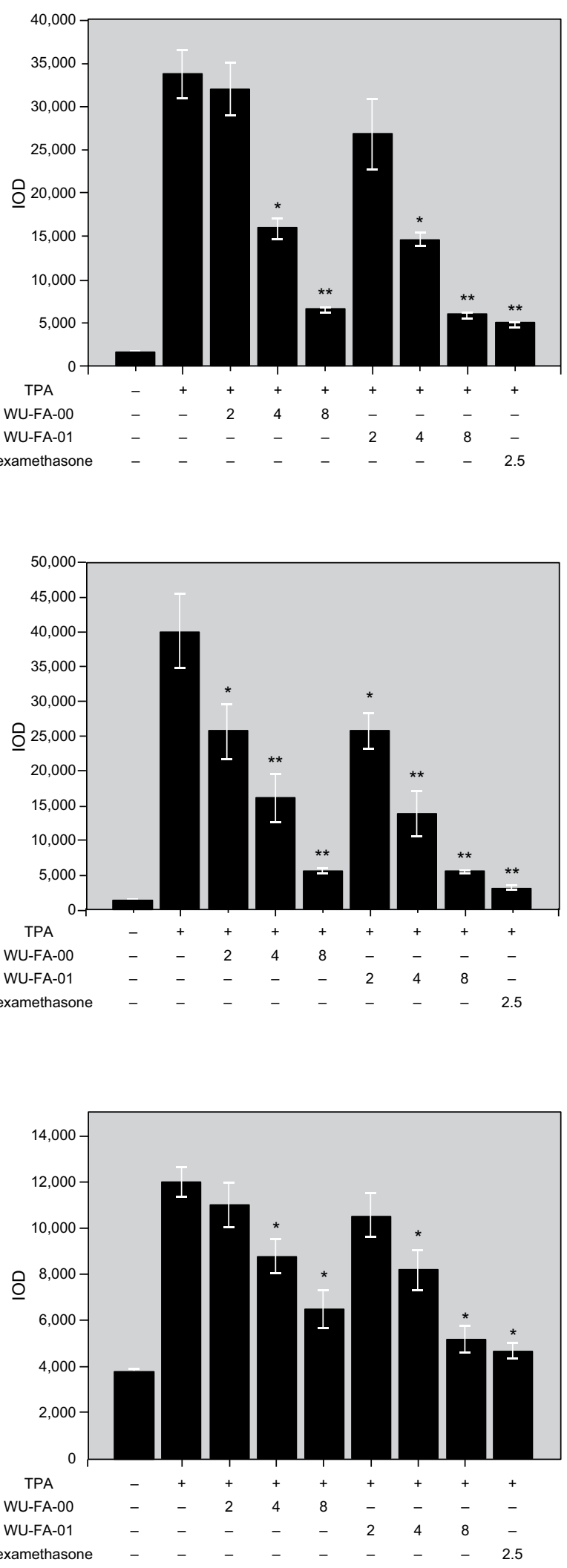

Figure 5 Effects of WU-FA-00 and WU-FA-0I treatment on proinflammatory cytokines' levels of TNF- $\alpha(\mathbf{A})$, IL-I $\beta$ (B), and COX-2 (C) in a mouse ear model.

Notes: Mouse ears treated with acetone, TPA, WU-FA-00, and WU-FA-OI at different concentrations were analyzed by immunohistochemical staining. The data are shown as mean \pm SD. Compared to the TPA-induced model group $(n=6)$, ${ }^{*}<0.05$ and $* * P<0.01$ (Dunnett's multiple comparison test). Magnification 200 $x$.

Abbreviation: TPA, 12-0-tetradecanoylphorbol-13-acetate. 
the proinflammatory cytokine levels of TNF- $\alpha$, IL- $1 \beta$, and COX- 2 between the treated groups and the control group in the TPA-induced mouse ear model were increased 20.37-, 31.47-, and 3.16-fold. First, 2,000, 4,000, and 8,000 $\mu \mathrm{g} /$ $\mathrm{mL}$ of WU-FA-00 retarded TPA-induced overexpression of TNF- $\alpha$ by $5.1,52.9$, and $80.7 \%$, while $2,000,4,000$, and $8,000 \mu \mathrm{g} / \mathrm{mL}$ of WU-FA-01 retarded TPA-induced overexpression of TNF- $\alpha$ by $20.5,56.5$, and $82.5 \%$ relative to the TPA group, respectively (Figure 5A). Second, WU-FA-00 at $2,000,4,000$, and $8,000 \mu \mathrm{g} / \mathrm{mL}$ greatly reduced the overexpression of IL- $1 \beta$ by $36.0,59.8$, and $86.1 \%$, while 2,000 , 4,000 , and $8,000 \mu \mathrm{g} / \mathrm{mL}$ of WU-FA-01 greatly reduced the overexpression of IL- $1 \beta$ by $35.9,65.6$, and $86.6 \%$, respectively (Figure 5B). Third, 2,000, 4,000, and 8,000 $\mu \mathrm{g} / \mathrm{mL}$ of WU-FA-00 retarded TPA-induced overexpression of COX-2 by $8.3,26.7$, and $45.8 \%$, while $2,000,4,000$, and $8,000 \mu \mathrm{g} /$ $\mathrm{mL}$ of WU-FA-01 retarded TPA-induced overexpression of COX-2 by $12.1,31.6$, and $56.6 \%$, compared to the TPA group, respectively (Figure 5C). Therefore, the above results indicate that WU-FA-00 and WU-FA-01 could markedly suppress the overexpression of proinflammatory cytokines, which was in accordance with the previous results of ear weight and ear thickness (Figure 3) and histological changes (Figure 4) in this TPA-induced ear model.

\section{Inhibition of TPA-induced expression of $\mathrm{p} 65, \mathrm{I} \mathrm{K} \mathrm{B}-\alpha$, and $\mathrm{p}-\mathrm{I} \mathrm{KB}-\alpha$}

The activation of NF- $\kappa \mathrm{B}$ is significant for the regulation of TNF- $\alpha$, IL-1 $\beta$, and COX- 2 overexpression in the TPA-induced inflammatory model. Therefore, whether WU-FA-00 and WU-FA-01 could affect the NF- $\kappa$ B signaling pathway was determined by immunohistochemical analysis. As illustrated in Figure 6A by red arrows, the results revealed that $\mathrm{p} 65$ was markedly suppressed by the treatment of WU-FA-00 and WU-FA-01, in which both WU-FA-00 and WU-FA-01 were more active at a concentration of $8,000 \mu \mathrm{g} / \mathrm{mL}$. Moreover, the results confirmed that the transcriptional activity was markedly upregulated in the TPA-induced model but was inhibited by WU-FA-00 and WU-FA-01 at $8,000 \mu \mathrm{g} / \mathrm{mL}$.

The signaling pathway of IKK is involved in the induction of proinflammatory cytokines via the modulation of NF- $\kappa B$. Thus, it is necessary to gain insights into the I $\mathrm{B}-\alpha / \mathrm{p}-\mathrm{I} \kappa \mathrm{B}-\alpha$ pathway in this TPA-induced model. From the immunohistochemical analysis in Figure $6 \mathrm{~B}$ and $\mathrm{C}$ at

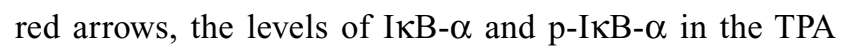
group were significantly increased. However, they could be suppressed by WU-FA-00 and WU-FA-01 in a dosedependent manner, especially at a higher concentration of $8,000 \mu \mathrm{g} / \mathrm{mL}$. I $\kappa \mathrm{B}-\alpha$ deletion, however, has no effect on $\mathrm{NF}-\kappa \mathrm{B}$ activation by most agents. Which kinase induces the phosphorylation of p65 is controversial, but protein kinase A, casein kinase II, IKK- $\alpha$, and IKK- $\beta$ have been implicated. The phosphorylation of p65 has been shown to be required for the TNF-induced transcriptional activity of NF- $\kappa B .{ }^{32}$ These results imply that both WU-FA-00 and WU-FA-01 might block the activation of NF- $\kappa B$ through interfering with p65 and I $\mathrm{I} B-\alpha / \mathrm{p}-\mathrm{I} \kappa \mathrm{B}-\alpha$ to inhibit the expression of the TPA-induced proinflammatory cytokines of TNF- $\alpha$, IL-1 $\beta$, and COX-2.

\section{Conclusion}

Both WU-FA-00 and WU-FA-01 not only possessed excellent in vitro antimicrobial activities for Gram-positive Staphylococcus strains but also exhibited effective inhibition effects in the TPA-induced mouse ear model. Thus, both WU-FA-00 and WU-FA- 01 could be considered as inhibitors of inflammation induced by bacterial infection. Moreover, it is possible that inflammation is frequently triggered by bacterial infection. The inhibitory effect of WU-FA-01 against microorganisms and TPA-induced skin inflammation is similar to its parent compound. The inhibitory effect of both compounds was associated with the suppression of TPA-stimulated proinflammatory cytokines of TNF- $\alpha$, IL-1 $\beta$, and COX-2. This study provides a further understanding of the anti-inflammatory properties of WU-FA-00 and WU-FA-01. Therefore, the results of this study implied that FA and the dihydro analog could be developed as difunctional agents, which possess both antimicrobial and anti-inflammatory activities.

\section{Acknowledgments}

Sincere and heartfelt thanks must go to Miss Sulian Liang who has given generous suggestions on the English language of the manuscript. This study was supported by National Natural Science Foundation of China (grant no 81803390), the Joint Research Project of Liverpool-Guangdong Drug Discovery Initiative (grant no 607140051), the Foundation of High-level Personnel Research Activation (grant no 2017RC04), and Youth Innovation Talents Program of Guangdong Province (grant no 2017KQNCX200). The authors are also grateful to the Foundation of Department of Education of Guangdong Province (grant nos 2016KCXTD005, 2017KSYS010, and 2017KQNCX200), the Youth Foundation of Wuyi University 
A
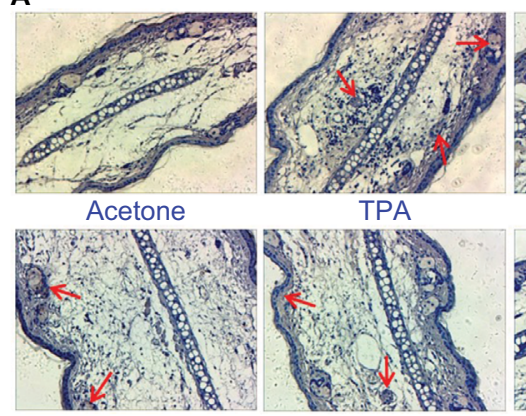

WU-FA-00-2

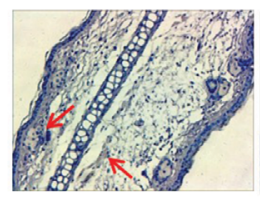

WU-FA-01-2

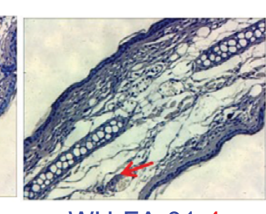

WU-FA-01-4

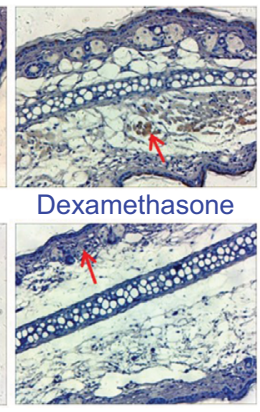

WU-FA-00-8

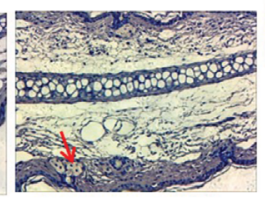

WU-FA-01-8

B
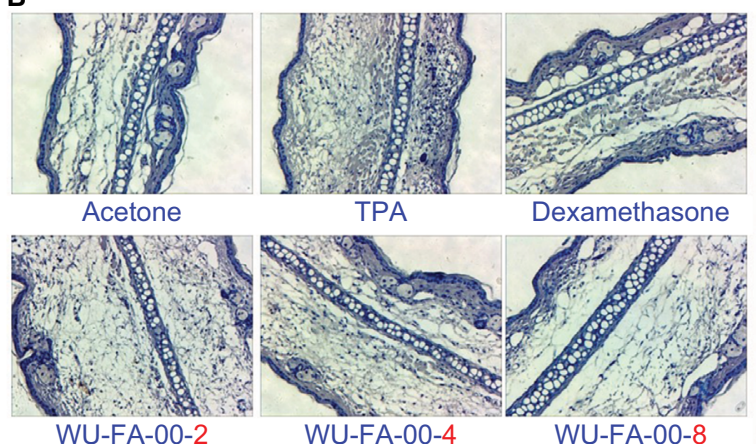

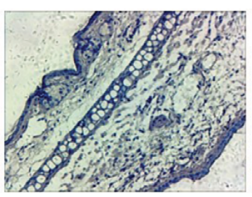

WU-FA-2H-2

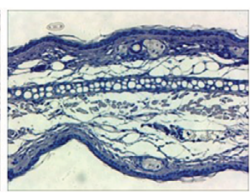

WU-FA-2H-4

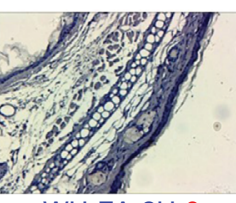

WU-FA-2H-8

C
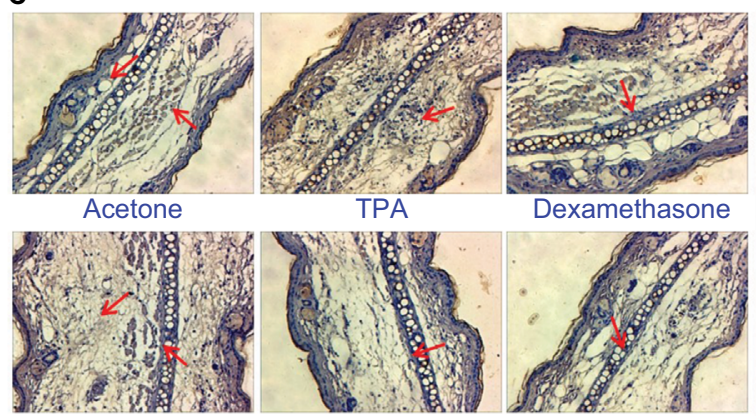

WU-FA-00-2
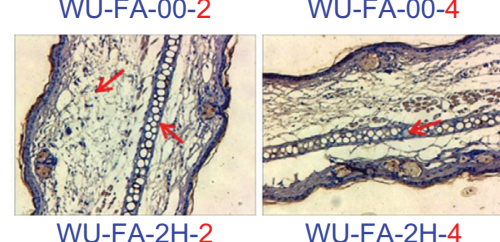

WU-FA-00-8

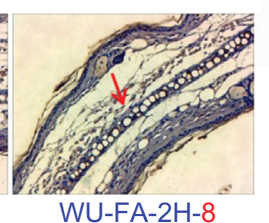

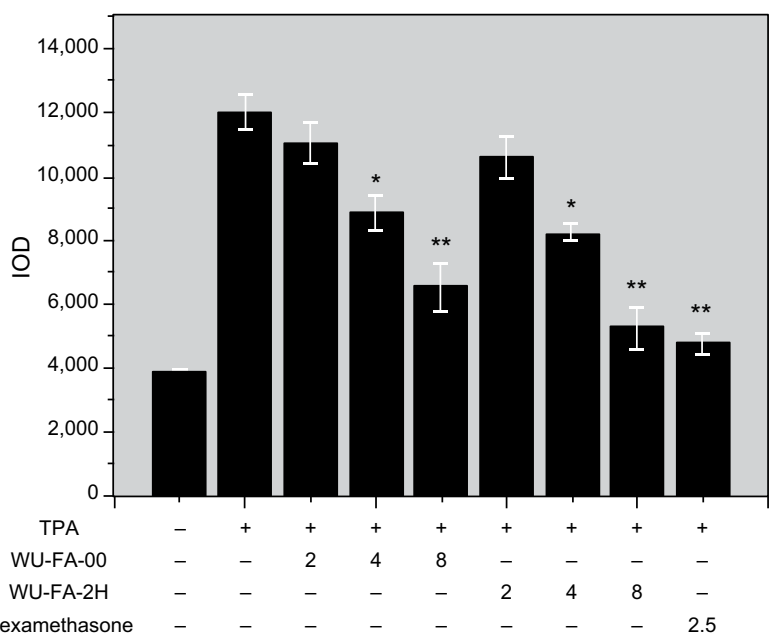
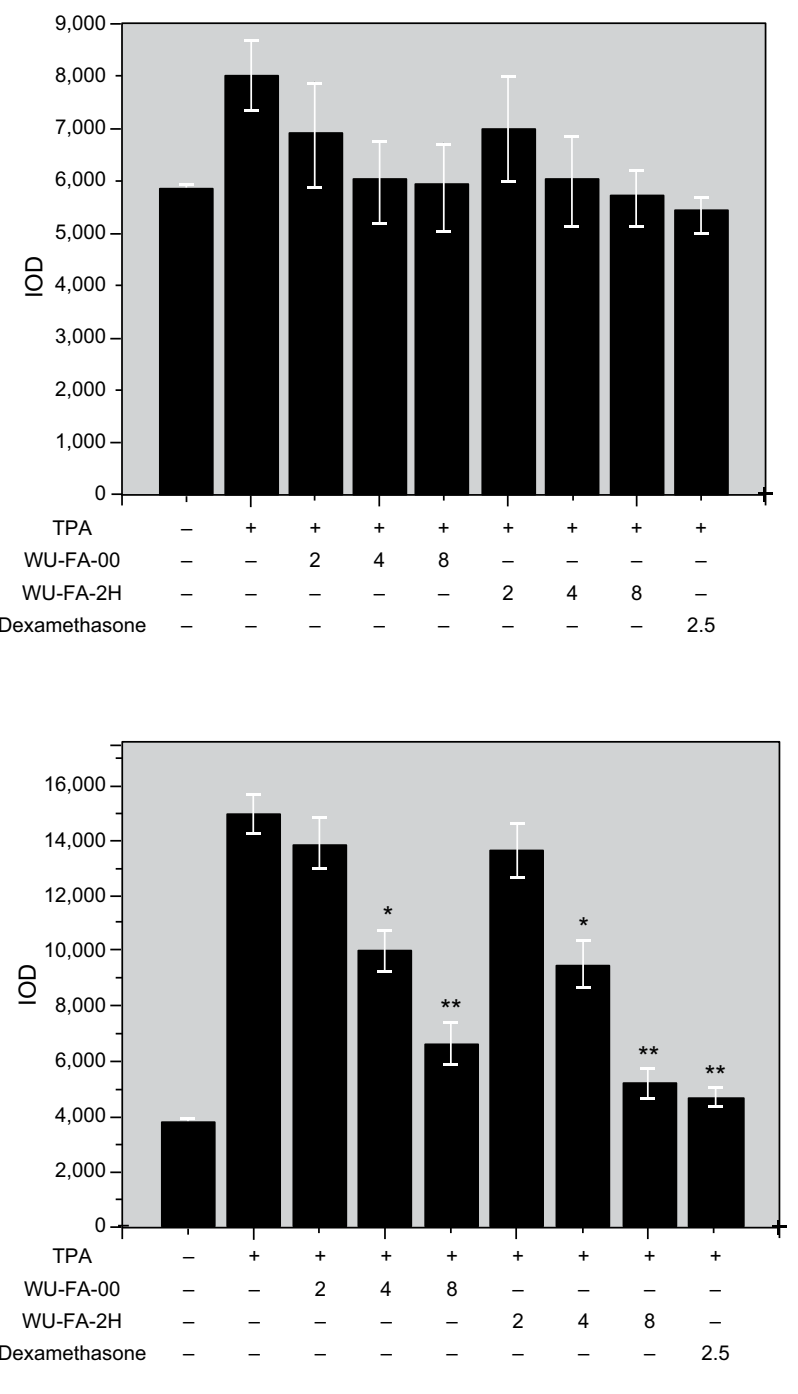

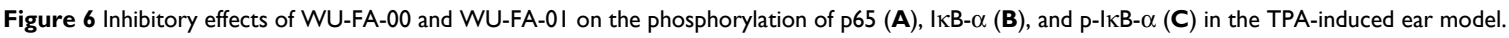

Notes: Mouse ears treated with acetone, TPA, WU-FA-00, and WU-FA-0I at different concentrations were analyzed by immunohistochemical staining. The data are shown as mean \pm SD. Compared to the TPA-induced model group $(n=6), * P<0.05, * * P<0.01$ (Dunnett's multiple comparison test). Magnification 200x. The arrows point to the the expression levels of key protein $(p 65$ and $p-\mid \kappa B-\alpha)$ in the pathway, using immunohistochemical analysis.

Abbreviation: TPA, 12-O-tetradecanoylphorbol-13-acetate; IOD, integral optical density. 
(grant no 2017td01), and the Doctor Research Activation Funding of Wuyi University (grant no 5011701521).

\section{Author contributions}

PPW and GYH performed the experimental work and drafted the manuscript. PPW, HH, TRW, BRT, and YYZ performed the bioactivity test. PPW, GYH, MG, DLL, JZ, and ZJS performed the experimental statistical analysis. WDH, XTX, and $\mathrm{KZ}$ directed and designed the manuscript. WDH, SAW, PMO, and SQZ coordinated the project. All authors contributed toward data analysis, drafting and critically revising the paper, gave final approval of the version to be published, and agree to be accountable for all aspects of the work.

\section{Disclosure}

The authors report no conflicts of interest in this work.

\section{References}

1. Lucas SM, Rothwell NJ, Gibson RM. The role of inflammation in CNS injury and disease. Br J Pharmacol. 2006;147(Suppl 1):S232-S240.

2. Tak PP, Firestein GS. NF-kappaB: a key role in inflammatory diseases. J Clin Invest. 2001;107(1):7-11.

3. Hansson GK. Inflammation, atherosclerosis, and coronary artery disease. N Engl J Med. 2005;352(16):1685-1695.

4. Hotamisligil GS. Inflammation and metabolic disorders. Nature. 2006;444(7121):860-867.

5. Hanada T, Yoshimura A. Regulation of cytokine signaling and inflammation. Cytokine Growth Factor Rev. 2002;13(4-5):413-421.

6. Hermanns HM, Wohlfahrt J, Mais C, Hergovits S, Jahn D, Geier A. Endocytosis of pro-inflammatory cytokine receptors and its relevance for signal transduction. Biol Chem. 2016;397(8):695-708.

7. Medeiros R, Otuki MF, Avellar MC, Calixto JB. Mechanisms underlying the inhibitory actions of the pentacyclic triterpene alpha-amyrin in the mouse skin inflammation induced by phorbol ester 12-O-tetradecanoylphorbol-13-acetate. Eur J Pharmacol. 2007;559(2-3):227-235.

8. Ahn EH, Kim DW, Kang HW, et al. Transduced PEP-1-ribosomal protein S3 (rpS3) ameliorates 12-O-tetradecanoylphorbol-13-acetate-induced inflammation in mice. Toxicology. 2010;276(3):192-197.

9. Akira S, Takeda K. Toll-like receptor signalling. Nat Rev Immunol. 2004;4(7):499-511.

10. Oeckinghaus A, Hayden MS, Ghosh S. Crosstalk in NF- $\kappa B$ signaling pathways. Nat Immunol. 2011;12(8):695-708.

11. Mizushina $Y$, Hirota M, Murakami $C$, et al. Some anti-chronic inflammatory compounds are DNA polymerase lambda-specific inhibitors. Biochem Pharmacol. 2003;66(10):1935-1944.

12. Nishida M, Nishiumi S, Mizushina Y, et al. Monoacetylcurcumin strongly regulates inflammatory responses through inhibition of NFkappaB activation. Int J Mol Med. 2010;25(5):761-767.

13. Jiang X, Takahashi N, Ando K, Otsuka T, Tetsuka T, Okamoto T. NF-kappa B p65 transactivation domain is involved in the NFkappa B-inducing kinase pathway. Biochem Biophys Res Commun. 2003;301(2):583-590.

14. Caivano M, Cohen P. Role of mitogen-activated protein kinase cascades in mediating lipopolysaccharide-stimulated induction of cyclooxygenase- 2 and IL-1 beta in RAW264 macrophages. J Immunol. 2000;164(6):3018-3025.

15. Nagatsu T, Sawada M. Inflammatory process in Parkinson's disease: role for cytokines. Curr Pharm Des. 2005;11(8):999-1016.

16. Etminan M, Gill S, Samii A. Effect of non-steroidal anti-inflammatory drugs on risk of Alzheimer's disease: systematic review and metaanalysis of observational studies. BMJ. 2003;327(7407):128.
17. Bessone F. Non-steroidal anti-inflammatory drugs: What is the actual risk of liver damage? World J Gastroenterol. 2010;16(45): 5651-5661.

18. Jeffcoach DR, Sams VG, Lawson CM, et al. Nonsteroidal anti-inflammatory drugs' impact on nonunion and infection rates in long-bone fractures. J Trauma Acute Care Surg. 2014;76(3):779-783.

19. Joyau C, van Wessem-Jouanneaux C, Asseray N, Veyrac G, Jolliet P. Non steroidal anti-inflammatory drugs (NSAIDs) and serious infectious risk. Fund Clin Pharmacol. 2014;28:103-103.

20. Barber M, Waterworth PM. Antibacterial activity in vitro of fucidin. Lancet. 1962;1(7236):931-932.

21. Godtfredsen WO, Jahnsen S, Lorck H, Roholt K, Tybring L. Fusidic acid: a new antibiotic. Nature. 1962;193:987.

22. Godtfredsen W, Roholt K, Tybring L. Fucidin: a new orally active antibiotic. Lancet. 1962;1(7236):928-931.

23. Collignon P, Turnidge J. Fusidic acid in vitro activity. Int J Antimicrob Agents. 1999;12(Suppl 2):S45-S58.

24. O'Neill AJ, Bostock JM, Moita AM, Chopra I. Antimicrobial activity and mechanisms of resistance to cephalosporin P1, an antibiotic related to fusidic acid. J Antimicrob Chemother. 2002;50(6):839-848.

25. Verbist L. The antimicrobial activity of fusidic acid. J Antimicrob Chemother. 1990;25(Suppl B):1-5.

26. Bendtzen K, Vesti-Nielsen N, Petersen J, Andersen V, Bendixen G. Treatment of chronic endogenous uveitis with fusidic acid. Lancet. 1991;337(8740):552-553.

27. Mohamed MF, Seleem MN. Efficacy of short novel antimicrobial and anti-inflammatory peptides in a mouse model of methicillin-resistant Staphylococcus aureus (MRSA) skin infection. Drug Des Devel Ther. 2014;8:1979-1983.

28. Kuo DH, Lai YS, Lo CY, Cheng AC, Wu H, Pan MH. Inhibitory effect of magnolol on TPA-induced skin inflammation and tumor promotion in mice. J Agric Food Chem. 2010;58(9):5777-5783.

29. Murakawa M, Yamaoka K, Tanaka Y, Fukuda Y. Involvement of tumor necrosis factor (TNF)-alpha in phorbol ester 12-O-tetradecanoylphorbol-13-acetate (TPA)-induced skin edema in mice. Biochem Pharmacol. 2006;71(9):1331-1336.

30. Stanley PL, Steiner S, Havens M, Tramposch KM. Mouse skin inflammation induced by multiple topical applications of 12-O-tetradecanoylphorbol-13-acetate. Skin Pharmacol. 1991;4(4):262-271.

31. Godtfredsen WO, Von Daehne W, Tybring L, Vangedal S. Fusidic acid derivatives. I. Relationship between structure and antibacterial activity. J Med Chem. 1966;9(1):15-22.

32. Takada Y, Mukhopadhyay A, Kundu GC, Mahabeleshwar GH, Singh S, Aggarwal BB. Hydrogen peroxide activates NF-kappa B through tyrosine phosphorylation of I kappa B alpha and serine phosphorylation of p65: evidence for the involvement of I kappa B alpha kinase and Syk protein-tyrosine kinase. J Biol Chem. 2003;278(26): 24233-24241.

33. Benamrouche N, Lazri M, Tali-Maamar H, Rahal K. Comparaison de la sensibilité aux antibiotiques de Corynebacterium diphtheriae par les méthodes de dilution en bouillon et de diffusion (E-test et disques) [Comparison of Corynebacterium diphtheriae susceptibility testing to antibiotics by the broth dilution and diffusion (E-test and disk) methods]. Med Mal Infect. 2014;44(8):392-393. French.

34. Gaudreau C, Girouard Y, Gilbert H, Gagnon J, Bekal S. Comparison of disk diffusion and agar dilution methods for erythromycin, ciprofloxacin, and tetracycline susceptibility testing of Campylobacter coli and for tetracycline susceptibility testing of Campylobacter jejuni subsp. jejuni. Antimicrob Agents Chemother. 2008;52(12):4475-4477.

35. Luangtongkum T, Morishita TY, El-Tayeb AB, Ison AJ, Zhang Q. Comparison of antimicrobial susceptibility testing of Campylobacter spp. by the agar dilution and the agar disk diffusion methods. J Clin Microbiol. 2007;45(2):590-594.

36. Meng Y, Hou X, Lei J, et al. Multi-functional Liposomes Enhancing Target and Antibacterial Immunity for Antimicrobial and Anti-Biofilm Against Methicillin-Resistant Staphylococcus aureus. Pharm Res. 2016;33(3):763-775. 
37. Sader HS, Fritsche TR, Jones RN. Daptomycin bactericidal activity and correlation between disk and broth microdilution method results in testing of Staphylococcus aureus strains with decreased susceptibility to vancomycin. Antimicrob Agents Chemother. 2006;50(7):2330-2336.

38. Chouaïb K, Hichri F, Nguir A, et al. Semi-synthesis of new antimicrobial esters from the natural oleanolic and maslinic acids. Food Chem. 2015;183:8-17.

39. Jabrane A, Ben Jannet H, Mastouri M, Mighri Z, Casanova J. Chemical composition and in vitro evaluation of antioxidant and antibacterial activities of the root oil of Ridolfia segetum (L.) Moris from Tunisia. Nat Prod Res. 2010;24(6):491-499.

40. Phee LM, Betts JW, Bharathan B, Wareham DW. Colistin and Fusidic Acid, a Novel Potent Synergistic Combination for Treatment of Multidrug-Resistant Acinetobacter baumannii Infections. Antimicrob Agents Chemother. 2015;59(8):4544-4550.
41. Theophel K, Schacht VJ, Schlüter M, et al. The importance of growth kinetic analysis in determining bacterial susceptibility against antibiotics and silver nanoparticles. Front Microbiol. 2014;5:544.

42. Liu W, Li Y, Zheng X, Zhang K, Du Z. Potent inhibitory effect of silibinin from milk thistle on skin inflammation stimuli by 12-O-tetradecanoylphorbol-13-acetate. Food Funct. 2015;6(12):3712-3719.

43. Wu X, Song M, Rakariyatham K, et al. Inhibitory Effects of 4'-Demethylnobiletin, a Metabolite of Nobiletin, on 12-O-Tetradecanoylphorbol13-acetate (TPA)-Induced Inflammation in Mouse Ears. J Agric Food Chem. 2015;63(51):10921-10927.

44. Ouyang N, Williams JL, Tsioulias GJ, et al. Nitric oxide-donating aspirin prevents pancreatic cancer in a hamster tumor model. Cancer Res. 2006;66(8):4503-4511.
Infection and Drug Resistance

\section{Publish your work in this journal}

Infection and Drug Resistance is an international, peer-reviewed openaccess journal that focuses on the optimal treatment of infection (bacterial, fungal and viral) and the development and institution of preventive strategies to minimize the development and spread of resistance. The journal is specifically concerned with the epidemiology of antibiotic

\section{Dovepress}

resistance and the mechanisms of resistance development and diffusion in both hospitals and the community. The manuscript management system is completely online and includes a very quick and fair peerreview system, which is all easy to use. Visit http://www.dovepress.com/ testimonials.php to read real quotes from published authors. 